\title{
Synthesis of Molecular Brushes by “Grafting Onto" Method: Combination of ATRP and Click Reactions
}

\author{
Haifeng Gao and Krzysztof Matyjaszewski* \\ Department of Chemistry, Carnegie Mellon University, 4400 Fifth Avenue, Pittsburgh, \\ Pennsylvania 15213 \\ * Corresponding author. Email: km3b@andrew.cmu.edu
}

\section{Experimental}

Materials. Styrene (S, 99\%, Aldrich), $n$-butyl acrylate (BA, 99\%, Aldrich), and 2-hydroxyethyl methacrylate (HEMA, 98\%, Aldrich) were purified twice by passing the monomers through a column filled with basic alumina to remove the inhibitor. $\mathrm{CuBr}$ (98\%, Acros) and $\mathrm{CuCl}$ (98\%, Aldrich) were purified using a modified literature procedure. ${ }^{1}$ All other reagents: ethyl 2-bromoisobutyrate (EBiB), $N, N, N{ }^{\prime}, N{ }^{\prime \prime}, N$ '”pentamethyldiethylenetriamine (PMDETA), 2,2'-bipyridyne (bpy), $\mathrm{CuCl}_{2}$, methanesulfonyl chloride, triethylamine, sodium azide, tetrabutylammonium iodide, $N$, $N$ '-dicyclohexylcarbodiimide (DCC), pentynoic acid, 4-dimethylaminopyridine (DMAP) and solvents were purchased from Aldrich with the highest purity and used as received without further purification. Poly(ethylene glycol) monomethyl ether (PEO-OH) with different molecular weights were purchased from Fluka and used as received. Azidoterminated polystyrene (PS-N ${ }_{3}$ ) with $\mathrm{M}_{\mathrm{n}}=1,260 \mathrm{~g} / \mathrm{mol}$ and $\mathrm{M}_{\mathrm{w}} / \mathrm{M}_{\mathrm{n}}=1.04$ and azidoterminated poly( $n$-butyl acrylate) $\left(\mathrm{PBA}^{-\mathrm{N}_{3}}\right)$ with $\mathrm{M}_{\mathrm{n}}=2,110 \mathrm{~g} / \mathrm{mol}$ and $\mathrm{M}_{\mathrm{w}} / \mathrm{M}_{\mathrm{n}}=1.07$ 
(determined by THF GPC with linear PS as standards) were synthesized according to previous reports. $^{2}$ Special care should be taken not to heat the azido-containing compound above $75-80{ }^{\circ} \mathrm{C}$ because of its explosive nature at elevated temperatures. Dialkyne-, trialkyne- and tetraalkyne-containing coupling compounds were synthesized previously (Scheme 1S). ${ }^{3}$<smiles>CC#CCCC(=O)OCCSC(C)(C)C</smiles>

1

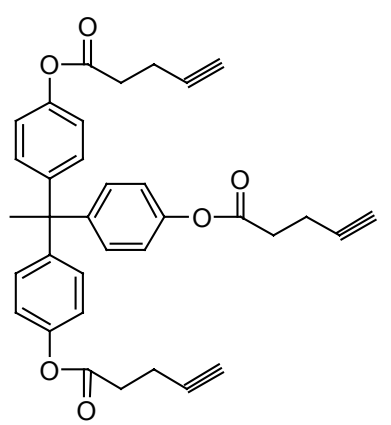

2

Trialkyne

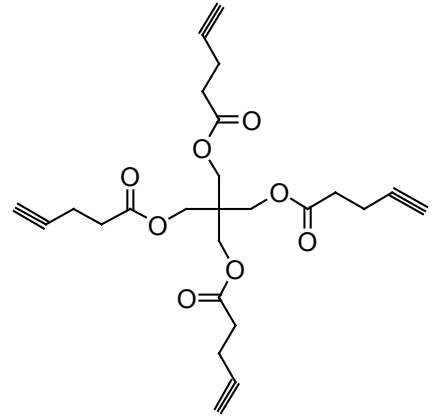

3

Scheme 1S. Structure of multifunctional alkyne-containing coupling compounds ${ }^{3}$

Synthesis of PHEMA linear polymers by ATRP. A clean and dry Schlenk flask was charged with HEMA (10 mL, $0.082 \mathrm{~mol})$, bpy (51.5 mg, $0.330 \mathrm{mmol})$, methanol (4.0 $\mathrm{mL})$ and 2-butanone $(6 \mathrm{~mL})$. The flask was deoxygenated by five freeze-pump-thaw cycles. During the final cycle, the flask was filled with nitrogen before $\mathrm{CuCl}(13.1 \mathrm{mg}$, $0.132 \mathrm{mmol})$ and $\mathrm{CuCl}_{2}(4.4 \mathrm{mg}, 0.033 \mathrm{mmol})$ were quickly added to the frozen mixture. Special care was not taken to avoid moisture condensation. The flask was sealed with a glass stopper then evacuated and back-filled with nitrogen five times before it was immersed in an oil bath at $50{ }^{\circ} \mathrm{C}$. Finally the $\mathrm{N}_{2}$-purged initiator EBiB $(24.2 \mu \mathrm{L}, 0.165$ mmol) was injected into the reaction system via a syringe through the side arm of the Schlenk flask. At timed intervals, samples were withdrawn via a syringe for measurement 
of monomer conversions and polymer molecular weights by GC and GPC, respectively. The reaction was stopped after $9.7 \mathrm{~h}$, at about $40 \%$ HEMA conversion, via exposure to air and dilution with methanol. The solution was filtered through a column filled with neutral alumina to remove the copper complex before the polymer was precipitated twice in cold THF and dried under vacuum at r.t. for two days. The PHEMA linear polymers had $\mathrm{M}_{\mathrm{n}, \mathrm{GPC}}=46,100 \mathrm{~g} / \mathrm{mol}$ and $\mathrm{M}_{\mathrm{w}} / \mathrm{M}_{\mathrm{n}}=1.22$, determined by DMF GPC with linear poly(methyl methacrylate) (PMMA) standards.

Synthesis of alkyne-functionalized PHEMA (PHEMA-alkyne). Linear PHEMA (1.5 g, 0.012 mol HEMA unit), DCC (4.92 g, 0.024 mol), pentynoic acid (2.34 g, $0.024 \mathrm{~mol}$ ) were added sequentially into $40 \mathrm{~mL}$ DMF before the flask was immersed into ice-water bath. Under magnetic stirring, $0.125 \mathrm{~g}$ DMAP in $3 \mathrm{~mL}$ DMF was added into this mixture within $5 \mathrm{~min}$. The reaction mixture was allowed to stir for $40 \mathrm{~h}$ at room temperature. During this period, the reaction mixture slowly turned into brown and the insoluble DCC urea precipitated out. After filtration to remove the solid, the polymer product was precipitated in water to remove the excessive pentynoic acid. After redissolving in THF, the polymers were precipitated again in hexane to remove the excessive DCC and DCC urea. Since the polymer product still had acidic smell, it was dissolved in methylene chloride. The organic solution was washed successively by 200 $\mathrm{mL} \mathrm{HCl}$ solution and $200 \mathrm{~mL} \mathrm{NaOH}$ solution before drying over anhydrous $\mathrm{MgSO}_{4}$ overnight. The methylene chloride was then removed in vacuo and $1.4 \mathrm{~g}$ product (yield: $57.8 \%)$ was obtained.

Synthesis of azido-terminated PEO (PEO-N $)_{3}$. A typical procedure for synthesis of PEO-N $\mathrm{N}_{3}$ with $\mathrm{M}_{\mathrm{n}} \sim 775 \mathrm{~g} / \mathrm{mol}\left(\mathrm{PEO}-\mathrm{N}_{3} 775\right.$ ) is briefly described. In a clean, 
dry round-bottom flask, PEO-OH $\left(\mathrm{M}_{\mathrm{n}} \sim 750 \mathrm{~g} / \mathrm{mol}, 13.7 \mathrm{~g}, 0.018 \mathrm{~mol}\right)$ was dissolved in $100 \mathrm{~mL}$ methylene chloride (dried overnight with $\mathrm{MgSO}_{4}$ ). The solution was cooled to 0 ${ }^{\circ} \mathrm{C}$ in ice-water bath before triethylamine $(5.00 \mathrm{~mL}, 0.036 \mathrm{~mol})$ and methanesulfonyl chloride $(2.80 \mathrm{~mL}, 0.036 \mathrm{~mol})$ were added sequentially. The flask was then removed from the ice-water bath and the reaction was allowed to proceed for $24 \mathrm{~h}$ at room temperature. During this period, the reaction mixture slowly turned yellowish and some solid precipitated out. After filtration to remove the solid, the reaction mixture was washed successfully with $300 \mathrm{~mL} 1 \mathrm{M} \mathrm{HCl}$ solution, $300 \mathrm{~mL} 1 \mathrm{M} \mathrm{NaOH}$ solution and $200 \mathrm{~mL} 1 \mathrm{M} \mathrm{NaCl}$ solution. The organic layer was dried over anhydrous $\mathrm{MgSO}_{4}$ overnight before the solvent was removed in vacuo, yielding a yellowish viscous liquid. The yield of the mesylate-terminated PEO (PEO-OSO $\mathrm{CH}_{3}$ ) was $12.8 \mathrm{~g}$ (yield: $85.9 \%$ ). Part of the PEO-OSO $\mathrm{CH}_{3}(8.3 \mathrm{~g}, 0.010 \mathrm{~mol})$ was dissolved in $40 \mathrm{~mL}$ DMF before sodium azide $(1.33 \mathrm{~g}, 0.020 \mathrm{~mol})$ and $0.15 \mathrm{~g}$ tetrabutylammonium iodide were added sequentially. The reaction mixture was stirred magnetically at $50{ }^{\circ} \mathrm{C}$ for $24 \mathrm{~h}$ before removal of $N, N$-dimethylformamide (DMF) by rotary evaporation. The solid was dissolved in methylene chloride and the undissolved solid was removed by filtration. The organic solution was washed twice by water before dried over anhydrous $\mathrm{MgSO}_{4}$

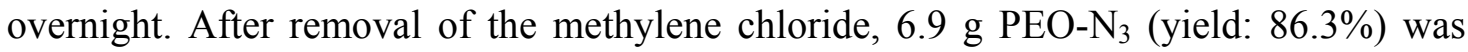
obtained, whose structure was verified by ${ }^{13} \mathrm{C}$ NMR spectroscopy $\left(\delta, \mathrm{CDCl}_{3}\right.$ as solvent): 70.5 ppm (s, $\left.\left(\mathrm{CH}_{2} \mathrm{CH}_{2} \mathrm{O}\right)_{\mathrm{n}}\right), 59.0$ ppm $\left(\mathrm{s}, \mathrm{CH}_{3} \mathrm{O}\right), 50.9 \mathrm{ppm}\left(\mathrm{s}, \mathrm{CH}_{2} \mathrm{CH}_{2} \mathrm{~N}_{3}\right)$. By using a similar procedure, PEO- $\mathrm{N}_{3}$ with $\mathrm{M}_{\mathrm{n}} \sim 2025 \mathrm{~g} / \mathrm{mol}\left(\mathrm{PEO}-\mathrm{N}_{3} 2025\right)$ was synthesized too.

Synthesis of azido-terminated PBA-b-PS block copolymers (PBA-b-PS-N $)_{3}$. PBA- $b$-PS-Br block copolymers containing bromine chain-end functionality $\left(\mathrm{M}_{\mathrm{n}}=3,900\right.$ 
$\mathrm{g} / \mathrm{mol}$ and $\mathrm{M}_{\mathrm{w}} / \mathrm{M}_{\mathrm{n}}=1.08$, determined by THF GPC with linear PS standards) were synthesized by ATRP of styrene using PBA-Br $\left(\mathrm{M}_{\mathrm{n}}=2,100 \mathrm{~g} / \mathrm{mol}\right.$ and $\left.\mathrm{M}_{\mathrm{w}} / \mathrm{M}_{\mathrm{n}}=1.06\right)$ as macroinitiator and $\mathrm{CuBr} / \mathrm{PMDETA}$ as catalyst. After purification, the resulting polymer was dissolved in DMF, $\mathrm{NaN}_{3}$ (2 times excess to the mole of bromo groups) was added, and the resulting solution was allowed to stir at $25{ }^{\circ} \mathrm{C}$ overnight. After precipitation into methanol/water mixture (1/1 by volume), PBA- $b-\mathrm{PS}-\mathrm{N}_{3}$ was obtained.

Synthesis of brush polymers via click coupling reactions between azidoterminated polymer chains and PHEMA-alkyne. A typical procedure for synthesis of PHEMA-g-PEO grafted copolymers was started with the ratio of reagents [PEO$\left.\mathrm{N}_{3}\right]_{0} /[\mathrm{HEMA}-\text { alkyne }]_{0} /[\mathrm{CuBr}]_{0} /[\mathrm{PMDETA}]_{0}=1.80 / 1 / 0.33 / 0.33$. The click coupling reactions between PEO-N 775 (229 mg, $0.295 \mathrm{mmol})$ and PHEMA-alkyne (34.6 mg, 0.164 mmol HEMA-alkyne unit) were conducted in a $10 \mathrm{~mL}$ Schlenk flask with $1 \mathrm{~mL}$ DMF as solvent and $\mathrm{CuBr} / \mathrm{PMDETA}$ as catalyst. Toluene $(0.05 \mathrm{~mL})$ was added initially into the reaction system as internal standard for calculation of the percentage of reacted PEO-N $\mathrm{N}_{3}$ SCs via DMF GPC measurement of the samples withdrawn periodically from the flask. After $10 \mathrm{~h}$, the polymer solution was exposed to air, diluted with THF, and passed through neutral alumina to remove the copper catalyst. The PHEMA- $g$-PEO brush polymers were purified by dialysis against $\mathrm{MeOH}$ to remove the unreacted $\mathrm{PEO}-\mathrm{N}_{3}$ chains. After purification, the solvent was removed by rotary evaporation, and the final product was dried under vacuum for two days.

Characterization. HEMA conversions were determined using a Shimadzu GC14A gas chromatograph, equipped with a capillary column (DB-Wax, $30 \mathrm{~m} \times 0.54 \mathrm{~mm} \times$ $0.5 \mu \mathrm{m}, \mathrm{J} \& \mathrm{~W}$ Scientific) and the ATRP solvent (mixture of methanol and 2-butanone) 
was used as an internal standard. The apparent molecular weights of different polymer species were determined by GPC equipped with HPLC pump at flow rate of $1 \mathrm{~mL} / \mathrm{min}$ DMF or THF (Waters, 515), and four columns (guard, $10^{5} \AA, 10^{3} \AA$, and $100 \AA \AA$; Polymer Standards Services) in series. Toluene was used as GPC internal standard. A calibration curve based on linear PS or PMMA standards was used in conjunction with a differential refractive index (RI) detector (Waters, 2410). A triple detector system connected with a THF GPC was employed to measure the absolute molecular weights $\left(\mathrm{M}_{\mathrm{w}, \mathrm{MALLS}}\right)$ of polymers. The detectors include a RI detector (Wyatt Technology, Optilab REX), a viscometer detector (Wyatt Technology, ViscoStar) and a multi-angle laser light scattering (MALLS) detector (Wyatt Technology, DAWN EOS) with the light wavelength at $690 \mathrm{~nm}$. Absolute molecular weights were determined using ASTRA software from Wyatt Technology. ${ }^{1} \mathrm{H}$ NMR or ${ }^{13} \mathrm{C}$ NMR spectra of the polymer solutions in $\mathrm{CDCl}_{3}$ or DMF- $d_{7}$ were collected on Bruker Avance $300 \mathrm{MHz}$ spectrometer at $27^{\circ} \mathrm{C}$. 


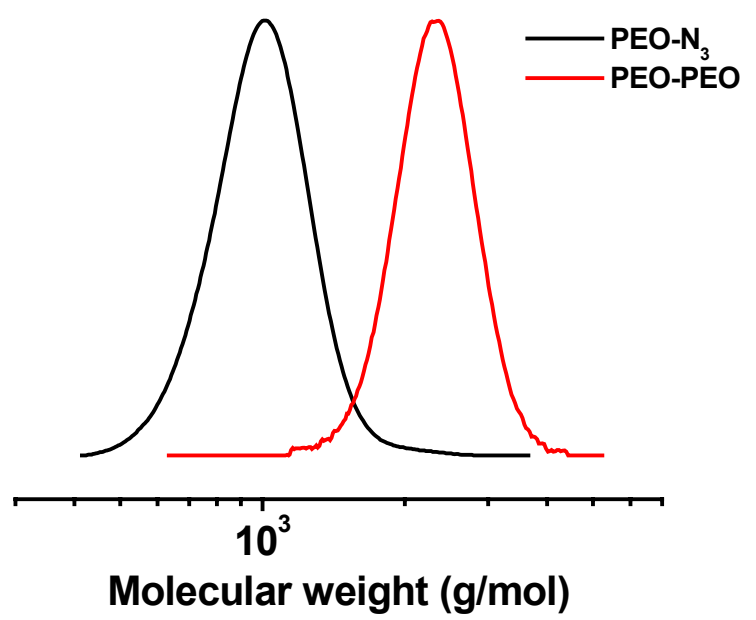

Figure 1S. GPC curves of PEO-N $\mathrm{N}_{3} 775$ and its coupling product with 1 by click coupling reaction; experimental conditions: $\left[\mathrm{PEO}-\mathrm{N}_{3} \quad 775\right]_{0} /[\mathbf{1}]_{0} /[\mathrm{CuBr}]_{0} /[\mathrm{PMDETA}]_{0}=$ 1/0.5/0.33/0.33; $\left[\text { PEO-N }{ }_{3} 775\right]_{0}=0.25 \mathrm{M}$, r.t. in DMF; linear PMMA standards were used for calibration of the THF GPC.

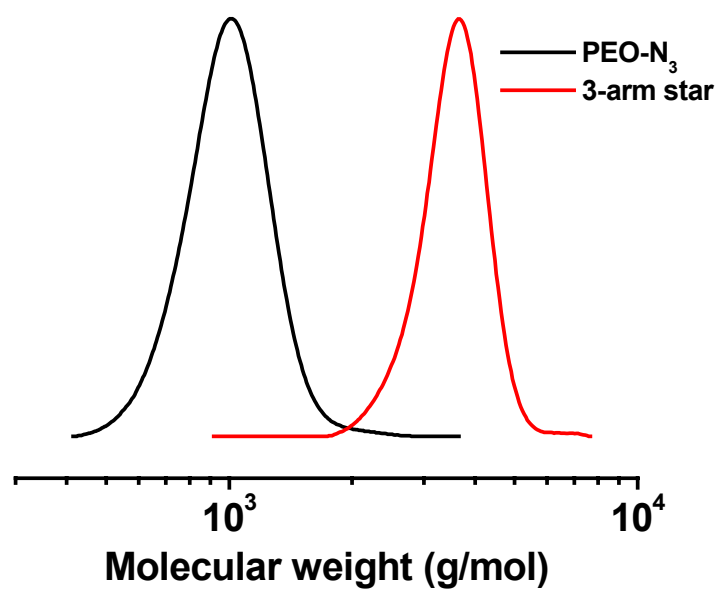

Figure 2S. GPC curves of PEO-N 775 and its coupling product with 2 by click coupling reaction; experimental conditions: $\left[\mathrm{PEO}-\mathrm{N}_{3} \quad 775\right]_{0} /[\mathbf{2}]_{0} /[\mathrm{CuBr}]_{0} /[\mathrm{PMDETA}]_{0}=$ 1/0.33/0.33/0.33; [PEO-N $\left.{ }_{3} 775\right]_{0}=0.25 \mathrm{M}$, r.t. in DMF; linear PMMA standards were used for calibration of the THF GPC. 


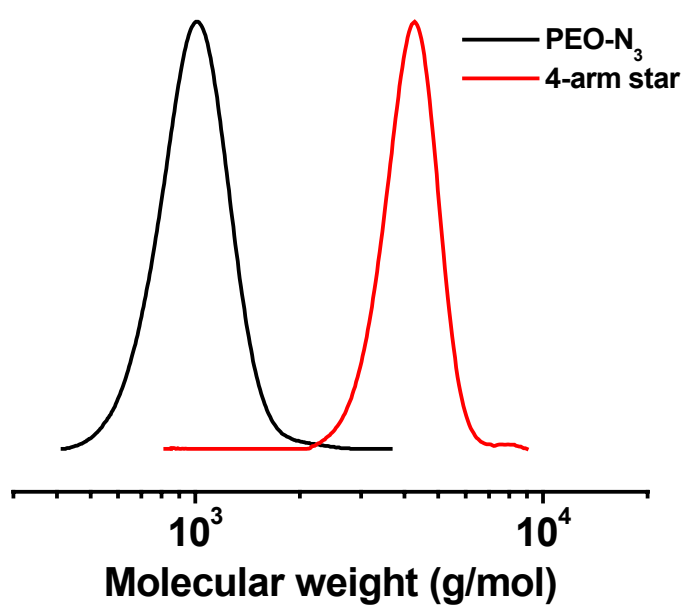

Figure 3S. GPC curves of PEO-N $\mathrm{N}_{3} 775$ and its coupling product with $\mathbf{3}$ by click coupling reaction; experimental conditions: $\left[\mathrm{PEO}-\mathrm{N}_{3} \quad 775\right]_{0} /[3]_{0} /[\mathrm{CuBr}]_{0} /[\mathrm{PMDETA}]_{0}=$ 1/0.25/0.33/0.33; [PEO-N $\left.{ }_{3} 775\right]_{0}=0.25 \mathrm{M}$, r.t. in DMF; linear PMMA standards were used for calibration of the THF GPC. 


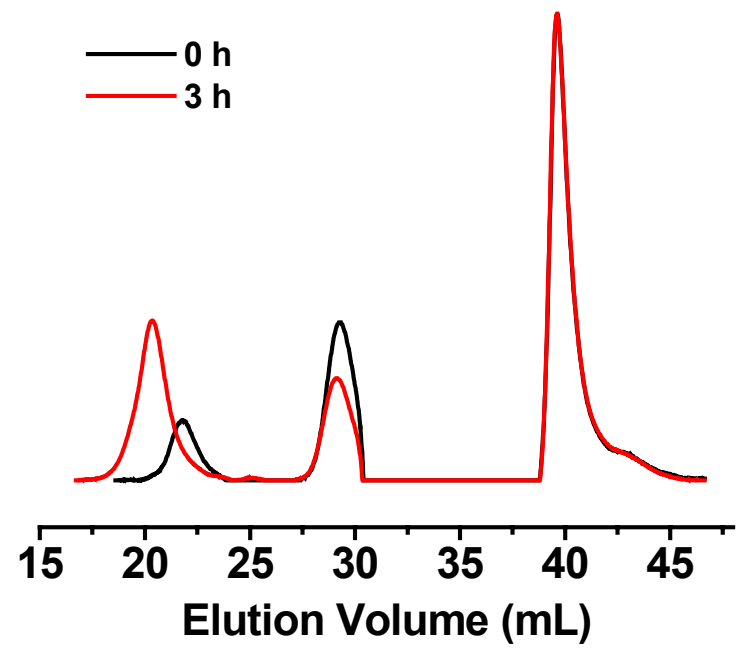

Figure 4S. Calculation of the grafting density ( $\mathrm{Y}_{\text {grafting }}$ ) of PHEMA-g-PEO brush polymers by GPC using toluene as internal standard; experimental conditions: (Table 2, entry B1-1.80) $\quad\left[\mathrm{PEO}-\mathrm{N}_{3} \quad 775\right]_{0} /[\text { HEMA-alkyne }]_{0} /[\mathrm{CuBr}]_{0} /[\text { PMDETA }]_{0}=$ 1.80/1/0.33/0.33; $\left[\mathrm{PEO}-\mathrm{N}_{3}\right.$ 775 $_{0}=0.25 \mathrm{M}$, r.t. in DMF; linear PMMA standards for DMF GPC calibration.

Results summary of Figure 4S

\begin{tabular}{|l|l|l|l|l|l|}
\hline Time $(\mathrm{h})$ & $\mathrm{A}_{1}(\%)^{\mathrm{a}}$ & $\mathrm{A}_{2}(\%)^{\mathrm{b}}$ & $\mathrm{A}_{1} / \mathrm{A}_{2}$ & Reacted PEO-N & $\mathrm{Y}_{\text {grafting }}$ \\
\hline 0 & 27.39 & 72.61 & 0.3772 & 0 & 0 \\
\hline 6 & 19.77 & 80.23 & 0.2464 & $34.7 \%$ & $62.5 \%$ \\
\hline
\end{tabular}

a. Area fraction of unreacted $\mathrm{PEO}-\mathrm{N}_{3}$

b. Area fraction of internal standard toluene

\section{References}

(1) Acar, M. H.; Matyjaszewski, K. Macromol. Chem. Phys. 1999, 200, 1094.

(2) Tsarevsky, N. V.; Sumerlin, B. S.; Matyjaszewski, K. Macromolecules 2005, 38, 3558.

(3) Gao, H.; Matyjaszewski, K. Macromolecules 2006, 39, 4960. 